\title{
TESTIMONIO Y DENUNCIA DE LA INTERNACIONALIZACIÓN DEL CONFLICTO EN DOS OBRAS NARRATIVAS REPRESENTATIVAS DE LA DICTADURA BRASILEÑA: REFLEXOS DO BAILE Y O QUE É ISSO, COMPANHEIRO?
}

\author{
POR \\ LizBeth SouzA-Fuertes \\ Baylor University
}

La narrativa de la dictadura brasileña se caracteriza por las ricas interrelaciones que se derivan de su doble función de denuncia y testimonio, al reflejar una realidad de opresión puesta de relieve por los autores a través de una perspectiva testimonial que se enmarca en una rica tradición ya existente en Latinoamérica. Constituye, al mismo tiempo, una reflexión amplia y completa sobre los acontecimientos más destacados de la segunda mitad del siglo pasado en el Brasil, tanto a nivel político como social, y una forma significativa de mantener viva la memoria de lo que ocurrió, dominando el aspecto crítico al presentar una sociedad degradada por una actuación golpista que crea una realidad claramente distópica.

En tanto que testimonial, esta narrativa viene definida por la existencia de un narrador o serie de narradores que reaccionan ante una situación de opresión en la realidad totalitaria de las dictaduras, mostrando las raíces profundas de las diversas dependencias, como es el caso de la subordinación de los gobiernos autocráticos al apoyo extranjero. De ahí la resonancia que las acciones en contra de los representantes diplomáticos de las naciones aliadas adquieren a nivel internacional, sobre todo en el terreno propagandístico.

Las dos obras, O que é isso, companheiro? (1979), deFernando Gabeira, y Reflexos do baile (1976), de Antônio Callado, tienen como eje conector, precisamente, la utilización del secuestro de diplomáticos extranjeros en el Brasil por parte de la guerrilla, con objeto de dar relevancia internacional a la lucha contra la represión fascista, aunque las interrelaciones entre ellas se extiendan a campos tan diversos como a las acciones $\mathrm{y}$ actitudes de los grupos revolucionarios, los fundamentos ideológicos en que se sustentan, o su carácter de denuncia. Además, en ambas, su temática está incardinada en los momentos históricos previos a su escritura. Habría que verlas inmersas en la lucha de afirmación nacional que tuvo lugar en las décadas de los sesenta y setenta en Brasil, y en la cual la literatura y la política no sólo con demasiada frecuencia se 
entremezclan, sino que el escritor se ve obligado a adoptar opciones políticas que de una u otra forma determinarán su obra.

El objetivo de este trabajo consistirá en estudiar cómo aparece reflejada la internacionalización del conflicto en estas narraciones-tanto explícita como implícitamente-y su influencia en el proceso revolucionario, así como evaluar la fundamentación ideológica que sustenta la confrontación entre dictadores y oponentes, incidiendo también en el papel jugado por los intelectuales críticos del régimen por su capacidad para rescatar la memoria nacional, su poder de denuncia y su actuación como agentes movilizadores y transformadores de la sociedad.

Un enfoque comparativo de ambas obras pone de relieve indudables similitudes tanto en lo que se refiere a la técnica narrativa utilizada, fuertemente influída por el periodismo, como a la orientación ideológica, claramente de izquierda, así como al planteamiento irónico con el que se expone la materia narrada. Las divergencias son también obvias, extendiéndose tanto a la estructura, fragmentaria en Reflexos do baile y lineal en $O$ que é isso, companheiro?, en el ritmo de la narración, muy dinámico y rápido en la obra de Gabeira y lento en la narración de Callado. Además, la multiplicidad de perspectivas que domina en Reflexos do baile nos permite ofrecer una visión amplia y objetiva de una realidad compleja, como fue el período de la dictadura, lo que contrasta con la perspectiva más focalizada y personal que define a $O$ que é isso, companheiro?, como consecuencia de su carácter autobiográfico, con toda la carga de subjetividad que conlleva.

Por otra parte, es destacable en ambas la importancia que adquiere el referente internacional, o sea, la internacionalización del conflicto en sus variadas facetas, poniendo de relieve las servidumbres de la política brasileña durante la dictadura. El secuestro del embajador estadounidense, acción sobre la que gira la trama en ambas obras, no sólo suponía una novedad en las tácticas de la guerrilla en el Brasil, sino que comprometía seriamente las relaciones del Brasil con los Estados Unidos, cuyo apoyo era fundamental, a la vez que deterioraba la imagen de las dictaduras.

La internacionalización del conflicto es el resultado y respuesta a la persistente y profunda intervención de los Estados Unidos en la política interna de los países del Cono Sur en las décadas de 1960 y 1970 . No es fácil comprender la transcendencia del secuestro del embajador estadounidense si no valoramos el tremendo protagonismo alcanzado por la acción de los Estados Unidos en el área. Proyectadas ambas obras sobre un período clave de la historia moderna del Brasil, el retrato que nos proporcionan de la sociedad vendrá definido por la polarización y el claro enfrentamiento entre la dictadura y las fuerzas opositoras.

La implicación personal de los autores en la lucha de resistencia contra la dictadura le proporciona a estas narrativas un carácter testimonial, que nos permite percibir la realidad desde la misma perspectiva ideológica. Antônio Callado y Fernando Gabeira

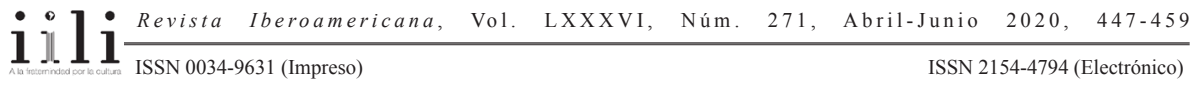


son intelectuales de izquierda que se opusieron al régimen militar desde el primer momento. Los dos participaron de forma decidida en la crítica a la dictadura desde la prensa, a través de los periódicos de oposición: Callado desde el Diário da manhã, junto a Otto Maria Carpeaux, Carlos Heitor Cony y Márcio Moreira, entre otros, y Gabeira desde el Jornal do Brasil, aunque este último se uniría a la guerrilla urbana al integrarse en el MR-8 (Movimento Revolucionário 8 de Outubro). Ambos autores también llevaron a sus narrativas la experiencia y el conocimiento de la realidad nacional que le proporcionaba su faceta de periodista. El periodismo se funde en sus obras con la historia reciente para proporcionarnos dos narrativas clave para entender el fenómeno de las dictaduras en el Brasil.

Reflexos do baile no sólo se nutre del periodismo, con todos sus recursos que van desde la fragmentación narrativa hasta el dinamismo expositivo o la mezcla de géneros, sino que recrea la historia haciendo una traslación de momentos históricos que nos retrotrae a la colonia y se enlaza con los sueños nostálgicos del ex diplomático Rufino Mascarenhas para insertar, finalmente, la realidad brasileña en el contexto internacional de la época de la dictadura a través de la actuación del grupo guerrillero por medio del secuestro del embajador estadounidense. Es por lo tanto una obra en la que se combinan tanto componentes que pertenecen a la novela epistolar como al periodismo, para proporcionarnos un amplio cuadro proyectado sobre la historia que nos permite evaluar la realidad de la situación de la dictadura al comienzo de la década de los 70 .

Publicada en 1976, fue considerada por su autor su novela más lograda. Cuando Callado hace balance de su obra, confiesa literalmente, al referirse a esta narración: "acho que um único romance meu tem força em si: Reflexos do baile" (Suzuki y Stycer). La trama se centra en el secuestro del embajador estadounidense en el Brasil. Lo que singulariza a esta obra es, justamente, la ruptura que supone con los procedimientos técnicos antes utilizados por Callado. A la tendencia anterior, caracterizada por estructuras lineales, personajes claramente definidos y situaciones claras en un mundo bien establecido, una sociedad brasileña reconocible, ahora se contrapondrá una estructura fragmentada, personajes, en ocasiones, más proyectados que definidos, y la plasmación de un mundo caótico, dentro del contexto de resistencia a la dictadura.

Reflexos do baile está definida por el uso innovador del lenguaje literario, la carencia de un personaje principal, y la riqueza de sus enfoques que se obtienen a través de elementos tan diversos como diarios, notas, documentos y cartas, en una amalgama de elementos que, aparentemente, no tienen una conexión lógica, aunque la búsqueda de las interrelaciones entre ellos suponga un desafío para el lector, que necesita desentrañarlas para poder comprender el mensaje. A esto habría que añadir la ruptura cronológica de la narración y la falta de un eje narrativo, ya que se apoya en dos hechos específicos: la visita de la reina de Inglaterra al Brasil en 1968 y el envío al Brasil de los huesos del Emperador Dom Pedro I en 1972 (Arrigucci 60), lo que

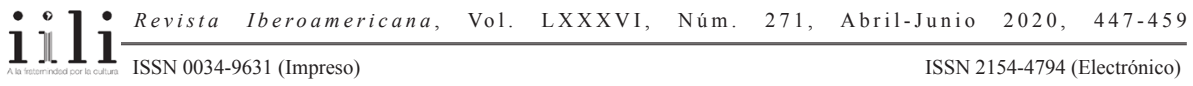


crea una narrativa confusa que se desenvuelve en un mundo cerrado y caótico, reflejo del propio mundo de la dictadura.

Esta obra debe ser valorada dentro de la secuencia narrativa que Callado inicia en 1967 con Quarup, ya que, aunque el autor comenzara a publicar sus novelas en la década de 1950, su importancia y consolidación como escritor sólo las consiga en la siguiente década. Su obra novelística desde la publicación de Quarup hasta Sempreviva, en 1981, abarca, precisamente, los momentos álgidos de la dictadura brasileña y representa no sólo un ejercicio de rechazo y denuncia a un régimen político autoritario, incompetente y degradado sino sobre todo un compromiso con los principios democráticos y los derechos sociales, en un vehemente intento de indagación centrado en temas claves de la cultura brasileña, entre los que destaca la problemática de la identidad nacional.

La resistencia a la dictadura adquiere en Reflexos do baile unas características específicas. Nos recuerda Davi Arrigucci Jr. cómo Callado fue capaz de montar con su obra un mosaico que es, a la vez, una novela histórica y política (63), adoptando específicamente la forma de una alegoría irónica (68), lo que explicaría, en su opinión, que los personajes no lleguen a ser configurados como "reales o complejos", al no poder liberarse de la abstracción que lleva implícita la construcción alegórica, aunque admita que dos de ellos sí alcanzan un indudable nivel de complejidad: Rufino y Juliana (71).

No obstante, tanto si enfatizamos el componente alegórico y el planteamiento irónico, o si destacamos las facetas política o testimonial, Reflexos do baile supone un indudable punto de inflexión en la producción de Callado y un indiscutible esfuerzo técnico por tratar de dar una visión amplia de una sociedad en conflicto. Esta fractura en la sociedad queda reflejada en la propia estructura de la novela.

Callado estableció el origen de esta estructura fragmentada, tanto en Reflexos do baile como en Bar Don Juan, específicamente en la "perda das ilusões" de los años 60:

É uma maneira diferente de você ver as coisas. Há uma diferença entre a confiança que você tem na sua capacidade de organizar o mundo na sua cabeça, pelo menos, de forma compreensível, e o momento que você começa a viver uma sucessão de acontecimentos, nos quais passou a faltar, de sua parte, uma esperança de organizálos e deles próprios uma falta de coesão, uma falta de sentido, que eu não acho só do Brasil, não, mas no Brasil aparece mais. (Cruz 6)

La fragmentación es el reflejo de una sociedad rota, quebrada, en el que el devenir histórico pierde su eficacia para resaltar momentos desconectados del pasado y de la tradición. Sería la constatación en la narrativa de una ruptura, tanto de valores como de tradiciones, produciendo, además, cierta sensación de caos, de sociedad privada de orden y de sentido, una sociedad donde se han roto los vínculos con el pasado, con su tradición y que, a la vez, carece de un plan de futuro. Esta fragmentación funciona,

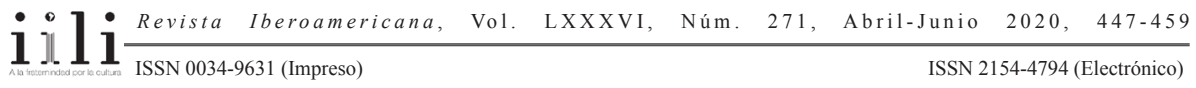


como ha señalado Vânia Pinheiro Chaves, "como metáfora do estilhaçamento da História do Brasil produzido pelo golpe militar que instaurou uma longa e cruel ditadura" (46).

En este mundo fragmentado, los personajes aparecen integrados primordialmente en tres grupos-los diplomáticos, los guerrilleros y los funcionarios-destacando las figuras de Juliana, hija del ex embajador brasileño Rufino Mascarenhas, organizadora del secuestro del embajador estadounidense, y el propio Rufino, soñador, nostálgico del pasado, insatisfecho con su realidad y su mundo, el cual nos permite adentrarnos en el mundo de la diplomacia. Mascarenhas es un representante del mundo diplomático que no difiere en exceso del resto de la sociedad. La mediocridad, las pasiones, los egoísmos y la vanidad van a ser las características que los definen. Como perteneciente a un grupo de élite respetado y consentido por el régimen militar, aparentemente no ha sufrido la contaminación moral que la sociedad en general ha experimentado. Sin embargo, tanto él como el Cuerpo Diplomático acreditado en Brasil revelan una clara despreocupación moral en relación con los asuntos internos del Brasil. Como ha señalado Arrigucci, lo que define a este grupo de diplomáticos es su completa desconexión y desinterés en relación con la realidad brasileña, así como su incapacidad para establecer vínculos profundos con el país, pudiendo interferir en sus asuntos internos, pero encerrándose en su mundo exclusivo, cerrado, un paraíso artificial, que produce completa alienación de la realidad nacional (69).

El planteamiento irónico de la novela permite vislumbrar un posicionamiento sumamente crítico del autor en relación con el Cuerpo Diplomático brasileñoprimordialmente reflejado a través de la figura de Rufino-que se correspondía con la realidad, puesto que el servicio diplomático vivió durante la dictadura una realidad paralela, derivada de su carácter elitista, lo que le permitió disfrutar de un status especial y vivir relativamente apartado de las miserias diarias de ese período. La represión interna llevada a cabo por la dictadura fuerza al exilio a numerosos opositores, lo que contribuye a ofrecer una nueva faceta de la internacionalización del conflicto al obligar al régimen militar a la creación de órganos de espionaje que tenían como objetivo la vigilancia y control de los nacionales en el exterior y que actuaron dentro o en directo contacto con el Ministerio de Asuntos Exteriores.

El estudio de Pio Penna Filho sobre las actividades del Centro de Informações do Exterior do Itamaraty (CIEX) y la represión en el Cono Sur entre los años 1966 y 1979, pone de manifiesto las implicaciones directas del servicio diplomático brasileño en actividades de espionaje y seguimiento de opositores durante la dictadura. Por otro lado, la aparición de los documentos en Paraguay en 1996, conocidos como "los archivos del terror", propició el desplome de un mito profundamente acendrado en la sociedad brasileña: que el Itamaraty (el Ministerio de Asuntos Exteriores brasileño) no colaboró, o lo hizo a pequeña escala, con el componente represor de la ditadura militar brasileña. La realidad es que su colaboración con la represión a partir de 1964

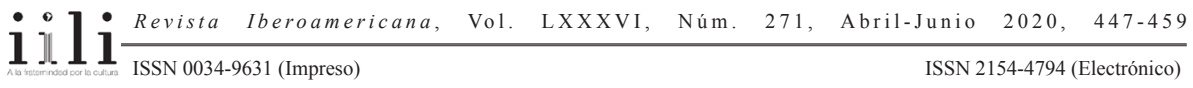


fue evidente e intensa, tanto en el proceso de depuración interna como en las labores de espionaje y control de los exiliados. Trabajó estrechamente con las agencias de la represión como el SNI (Serviço Nacional de Informações), el Ejército, la Marina y la Aviación a través de agencias especializadas como el CIEX, CENIMAR (Centro de Informações da Marinha), o CISA(Centro de Informações daAeronáutica). El complejo sistema de informaciones que los militares crearon y que actuaba primordialmente en el interior, tenía una vertiente internacional que contó con el apoyo decidido del Ministerio de Asuntos Exteriores (44).

La función principal del CIEX, órgano autónomo pero dependiente de Itamaraty, era vigilar y controlar los movimientos de los exiliados tanto en Europa, sobre todo en Portugal, como en América Latina o África. El Centro estaba integrado por personal del Ministerio, teniendo al mando a un diplomático de nivel intermedio y subordinado jerárquicamente al SNI. Por otro lado, la colaboración de Itamaraty con las agencias norteamericanas fue estrecha, como lo demuestra la existencia de varias carpetas en su archivo conteniendo documentos intercambiados entre el Brasil y las agencias estadounidenses sobre actividades políticas llevadas a cabo en América Latina y definidas como "comunistas" (Penna 46-8).

A la complejidad técnica y al carácter alegórico que caracterizan a Reflexos do baile, se opone la claridad estructural y el componente testimonial de $O$ que é isso, companheiro? En esta obra las propias vivencias de Gabeira sirven de telón de fondo a los hechos históricos que perfilaron a la dictadura. En otras palabras, es la mirada desencantada del militante de izquierda ante unos acontecimientos que rompieron el desarrollo histórico normal de la sociedad brasileña. De ahí la amplia gama de lecturas que ofrece: por un lado, es, indiscutiblemente, un documento de la represión militar fascista desde su inicio, con el golpe de estado de 1964; pero, por otro, es también un homenaje a las víctimas de la represión, una crítica de un sistema político corrupto que perpetúa la injusta estructura social, una reflexión sobre la tortura y sobre valores en los que se asentaba la civilización y que se resquebrajan. En el fondo, lo que se pone en tela de juicio son los valores mismos de la sociedad, la propia civilización brasileña. Gabeira resalta el poder destructivo de las dictaduras, asimilando el régimen dictatorial a gigantescos mecanismos establecidos para destruir a sus opositores, para inmediatamente expresar su repulsa ante una civilización que trataba así a sus ciudadanos (197), y confiesa finalmente que "nunca mais poderia pensar em ser brasileiro, sem levar en conta essa realidade. Depois da PE da Barão de Mesquita, todos nós, inocentes ou não, ficamos horrorizados com o Brasil e com o ser humano" (198).

La narración se centra en un período clave en el desarrollo de la dictadura en el Brasil, la década de los sesenta, y gira alrededor del secuestro en 1969 del embajador estadounidense Charles Burke Elbrick, ocurrido inmediatamente después de la aprobación del Ato Institucional No 5 (AI-5) en 1968. Promulgado por los militares,

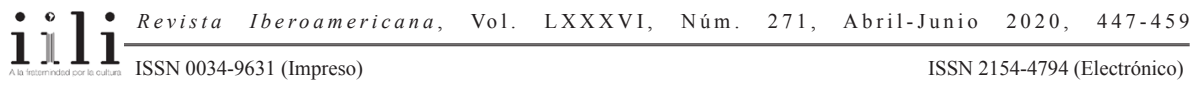


suprimió los derechos civiles e implantó la censura, lo cual supuso un cambio importante con relación a la actitud que los dictadores adoptaron con respecto a la cultura y la represión, y que va a encontrar una clara oposición en un sector de la intelectualidad brasileña que trata de mantener la identidad nacional ante la agresión cultural extranjera y el desinterés, e incluso la animosidad, de los militares con la cultura.

Será a partir de 1968 cuando la situación empeora radicalmente, al producirse una mudanza importante en la evolución de la dictadura. A partir de este año, lo que caracterizará este período hasta 1976 será la censura rígida y el aumento de la represión, dando, como resultado, la expulsión de sus puestos de profesores y funcionarios públicos. La situación sólo cambiará a partir de 1976, cuando se produzca un nuevo cambio como consecuencia de una mayor apertura política, el regreso de numerosos exiliados, la mayor libertad de prensa y la suavización de la presión sobre los escritores. El resultado sería el vacío cultural que caracterizó la década de los 70 .

La entrada en vigor del AI-5 tendrá un efecto especial en la vida de Fernando Gabeira como periodista y como militante de izquierda, al sufrir personalmente la tortura y asistir a los asesinatos de los miembros de la izquierda. Su integración en la guerrilla urbana carioca como miembro del MR-8 se produce tras un intenso debate personal en el que se valora la situación política del Brasil antes y después del golpe, y el papel jugado por las organizaciones políticas y sindicales en la lucha contra la dictadura. Esta contextualización del golpe se convierte en un elemento clave de la narrativa al servir de telón de fondo y justificación de la acción que dará notoriedad a este grupo: precisamente, el secuestro del embajador Elbrick, quien será permutado por quince presos políticos, contando para la realización del secuestro con el apoyo de guerrilleros experimentados de la Aliança Libertadora Nacional (ALN).

El carácter autobiográfico de la obra le confiere ciertos rasgos específicos derivados tanto de la subjetividad de las perspectivas como de su personal implicación en un hecho de tanta transcendencia política. Será justamente en estos aspectos en los que se sustentan las mayores críticas a la obra, sobre todo por las contradicciones en las que incurre y por la sesgada valoración de algunos personajes que, con frecuencia, caen en la caricatura como resultado del planteamiento maniqueísta de la narración. Es llamativa la perspectiva que se ofrece de los terroristas y del embajador estadounidense.

Quizás movido por el objetivo de desligarse de los terroristas de la imagen estereotipada de seres peligrosos, antisociales o fanatizados, Gabeira los presenta como un grupo de intelectuales de izquierda, idealistas, soñadores, que viven fuera de la realidad, sin una formación ideológica adecuada, recreándose en un comunismo puramente académico, sin ningún contacto con la realidad social, que juegan a la revolución sin haber disparado un tiro en su vida, como en realidad había ocurrido con el propio autor, y carentes de cualquier iniciativa militar o política.

En este texto lo que destaca no es tanto lo testimonial o lo puramente informativo, sino las posibilidades que ofrece de análisis de la realidad latinoamericana a partir de

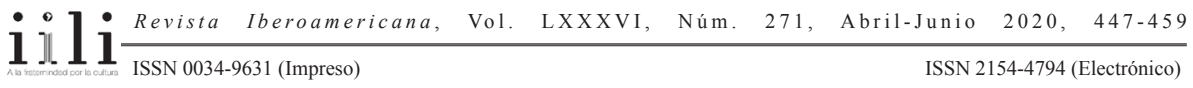


la realidad brasileña, sobre todo al valorar las responsabilidades de los dirigentes y el pueblo en las crisis brasileñas. Con referencia al golpe de estado de 1964, se analiza no solamente las responsabilidades del ejército, sino también de los partidos políticos, sobre todo los de la izquierda, las organizaciones sindicales, el pueblo y los intelectuales, al no ofrecer ninguno de ellos una respuesta contundente y clara, poniendo de relieve las manipulaciones políticas derivadas de los grandes centros de poder nacionales e internacionales.

Gabeira contempla su obra como parte de la responsabilidad del intelectual brasileño para con su pueblo. De ahí, la necesidad de escribir, porque es una forma de memoria histórica que impedirá el olvido y, por lo tanto, la impunidad. Sobre todo, él considera un deber ineludible del intelectual dar a conocer la represión feroz de las dictaduras, ejercida en la figura de destacados periodistas, escritores o empresarios por el simple motivo de oponerse a los dictadores, ejemplarizada en la tortura y la muerte.

Dieciocho años después de la publicación de $O$ que é isso, companheiro?, apareció la versión cinematográfica, titulada en inglés Four Days in September (1997), lo que contribuyó a dar proyección internacional a la problemática de la dictadura. Sorprendentemente, a pesar de haberse convertido en un referente del cine brasileño contemporáneo, ha recibido intensas críticas. Se le ha censurado la carencia de profundidad a la hora de analizar la dictadura militar de 1964, adoptando ante ella una posición ambigüa, poco crítica, sin aportar un posicionamiento ideológico claro. Además, se ha criticado el hecho de que se haya quedado en una interpretación ficcional de unos hechos históricos que no están suficientemente respetados. A esto habría que añadir las importantes diferencias de enfoque con la obra homónima de Gabeira, en la que se basa.

Por otro lado, la utilización de la cultura popular y los referentes estadounidenses fueron elementos importantes a la hora de transmitir el mensaje político. La versión edulcorada y manipulada de la realidad que nos ofrece la película-sobre todo en el caso de la caracterización del embajador estadounidense-nos remiten a los modelos hollywoodenses. También hay que señalar que el film no es capaz de transmitir de forma convincente la sordidez de la dictadura, ni los medios utilizados para anular a sus víctimas. De ahí que, precisamente, quede atenuada la intencionalidad de poner de manifiesto todo lo que de degradante e inhumano tienen las dictaduras. Esta película se inserta dentro de un contexto cultural brasileño como es el de las dos últimas décadas del siglo, en la que la literatura y el cine utilizan, en ciertas ocasiones, técnicas y enfoques más orientados a recrear artísticamente el mundo de la dictadura que a retratarlo de forma fidedigna.

Es un final de siglo que parece haberse desinteresado en conocer los entresijos de la dictadura y que contempla la represión, la tortura y el secuestro de los embajadores americanos como algo anecdótico, sobre el que se quiere pasar página cuando, en

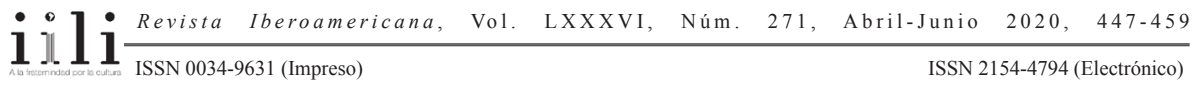


realidad, tuvo una influencia decisiva en el desarrollo histórico moderno del país. Será, indiscutiblemente, el secuestro de los dos embajadores lo que se constituya en el elemento conector fundamental entre las dos narrativas.

Estos secuestros fueron un reflejo de la absoluta dependencia que los gobiernos militares tenían de poderes extranjeros, sobre todo de los Estados Unidos. El secuestro de un cónsul o embajador adquiría una repercusión internacional indudable, afectando el prestigio del gobierno militar brasileño y las relaciones tanto con el vecino del Norte como con los países de su entorno.

El Brasil durante la dictadura se encuentra integrado en esta realidad supranacional. Por un lado, el país forma parte del sistema represor regional a través de la Operación Cóndor, que engloba a países tan diversos como Chile, Argentina, Paraguay, Uruguay y el propio Brasil; por el otro, su subordinación con respecto a los Estados Unidos en el contexto de la Guerra Fría es una realidad y, finalmente, el secuestro de embajadores, como parte de la campaña propagandística de la izquierda, pretende darle una proyección internacional a su protesta y lucha de resistencia contra las dictaduras, al integrarlo en la lucha de las izquierdas a nivel continental. No podemos olvidar que las dictaduras latinoamericanas de los 60 y 70 eran contempladas en el mundo libre como un anacronismo y estuvieron sometidas a un constante escrutinio por sus métodos represivos. La crítica que concitaba en Europa el régimen fascista de Franco en España es un buen ejemplo de la animadversión que despertaban los regímenes autoritarios.

Sin embargo, llama la atención el tratamiento dado a los embajadores americanos en ambas novelas, ofreciendo de ellos un perfil distorsionado que no se ajusta a la realidad. Tanto Gabeira como Callado, como periodistas involucrados en la lucha contra la dictadura, eran plenamente conscientes de la participación de los Estados Unidos en los golpes militares de Latinoamérica y de la intervención directa de los embajadores de este país en la preparación, asesoramiento y mantenimiento de las dictaduras. No obstante, en Oque é isso, companheiro? se ofrece una imagen edulcorada del embajador, y en Reflexo do baile se incide en aspectos personales del embajador o en la valoración que él y su familia tienen del Brasil sin prestar atención a aspectos claves para entender la realidad del momento, evitando profundizar en la actuación real de los embajadores como agentes de la potencia que favorecía, aleccionaba y dirigía, tanto la creación de las dictaduras como los métodos de represión.

Si algo caracteriza a Gabeira en $O$ que é isso, companheiro?, es su capacidad para proporcionar una mirada crítica a los hechos y personajes que protagonizaron la década de los 60, tanto a nivel nacional como continental. En su análisis de los años que preceden y siguen al golpe militar resalta la derrota de los gobiernos de izquierda a nivel continental. Dice expresamente: "Goulart caiu sem resistir; Getúlio se matou, Allende, mais tarde, se mataría também" (26), para luego insistir en la tesis del PCB (Partido Comunista Brasileiro) que consideraba que el golpe de estado del 64 "tinha sido um produto da união dos latifundiários com o imperialismo norte-americano" (36).

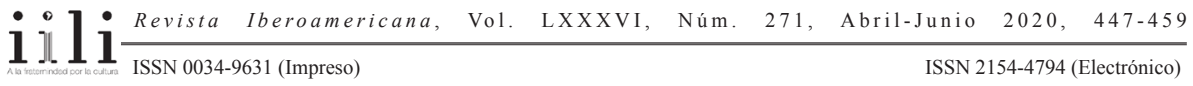


Partiendo de estos planteamientos, es difícil aceptar la descripción que se hace en esa obra del embajador americano como un ser equilibrado, culto, humano, dialogante, siempre digno y, sobre todo, ignorante absoluto de la realidad brasileña, como sugiere el autor al señalar que cuando se informó de las torturas en las cárceles brasileñas el embajador quedó "sinceramente impressionado com o que ouviu" (123), para añadir posteriormente: "O embaixador pouco conhecia a realidade brasileira” (127). Además, recoge la opinión defendiendo la idea del embajador, "de que os Estados Unidos não deveriam apostar en governos militares autoritários" ya que "esses governos garantiam uma estabilidade a curto prazo, mas eran capazes de despertar ódios eternos, que acabariam contaminando os seus aliados" (128). Estas son, supuestamente, las palabras y opiniones de un diplomático de carrera americano enviado expresamente a Brasil en plena Guerra Fría, representante del país que va a ser uno de los pilares de la dictadura y de las nuevas políticas a nivel internacional.

Callado, de forma similar, incide en aspectos de la personalidad del embajador estadounidense, Jack Clay, prácticamente intranscendentes. Arrigucci los resumió certeramente:

O embaixador americano que acaba sequestrado na casa do vizinho, tem do país uma visão estereotipada de turista superficial: lamenta-se pelo fato de as onças não serem tigres e não renderem melhor troféu de caça; passa o tempo cuidando de beija-flores, que depois serão vítimas de sua vingança de sequestrado; na verdade parece usar o país como esconderijo para safar-se de sua mulher, insatisfeita, queixosa e alcoólatra, e dar asas a seu homossexualismo, que obtém como troféu derradeiro um capixaba, tratador de beija-flores. (69-70)

Un estudio de la actuación del embajador americano en el Brasil, Lincoln Gordon (uno de los antecesores de Charles Elbrick en el cargo), en relación con la caída de Goulart y durante el periodo dictatorial, pone de manifiesto lo inconsistente e incluso contradictorio de esta aproximación a las figuras de los embajadores, sobre todo porque eran, sin duda, piezas básicas en el esquema de apoyo y coordinación entre las dictaduras en la estrategia de la Guerra Fría, claramente subordinada a los intereses de los Estados Unidos. Lo que daba uniformidad y poder a los países del Cono Sur fue su alineamiento con los Estados Unidos en su enfrentamiento con el comunismo y su fidelidad a la ideología de la Seguridad Nacional.

El intervencionismo directo de los Estados Unidos en Brasil, con una larga historia, que se retrotrae a la época de Getúlio Vargas, se intensifica en la década de los 60, sobre todo debido a la Guerra Fría y a las peculiaridades del gobierno de João Goulart. El temor de los Estados Unidos a que el mensaje comunista y los movimientos revolucionarios en un continente dominado por las desigualdades sociales, la injusticia social y el malgobierno calara en el pueblo-y esto era una realidad tangible debido a la

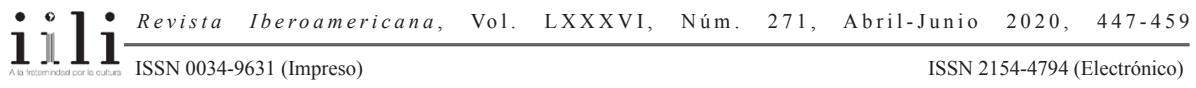


agresiva política de exportación de la revolución que tuvo su origen en la Revolución cubana-lleva al gobierno estadounidense a endurecer su política en América Latina, incluso durante el gobierno de John F. Kennedy, superando la política de equilibrios entre presión económica y política basada en la Alianza para el Progreso. Con la llegada al gobierno de Lyndon B. Johnson, la opción por el intervencionismo directo y la actuación militar se convierte en una realidad.

Pero ya a partir de 1962 hay un cambio de rumbo en la política exterior de los Estados Unidos como consecuencia de la oposición interna conservadora en el Brasil, las expropiaciones de bienes americanos y la nueva orientación en Washington del sector más radical. Los Estados Unidos, como señalan Rapoport y Laufer, a través de la CIA y la propia Embajada norteamericana, "modificarían su posición vacilante, pasando a colaborar activamente con grupos anti-Goulart como el IPES (Instituto de Investigaciones y Estudios Sociales) y el IBAD (Instituto Brasileño para la Acción Democrática), financiando su equipamiento y propaganda" (6), llevando a cabo no sólo una intensa labor de propaganda, sino también interfiriendo en las elecciones parlamentarias y estaduales de octubre del 62, decisivas porque en ellas se renovaría la totalidad de los Diputados, Senado y la mitad de las gobernaciones, en un proceso de clara desestabilización política (7). El embajador Gordon reconocería con posterioridad que los Estados Unidos “'invirtieron' unos 5 millones de dólares en la misión de torcer la voluntad electoral de parte significativa de la ciudadanía brasileña-otras fuentes calculan entre 12 y 20 millones de dólares-en su mayor parte proporcionados por la CIA" (7).

A todo esto habría que sumar una permanente campaña de desprestigio contra el gobierno de Goulart por parte de la diplomacia y los organismos estadounidenses de asistencia y, hacia el final de 1963, el Departamento de Estado toma la decisión de acelerar y orientar el golpe militar, para lo cual se nombra como agregado militar de la Embajada en Brasilia al general Vernon Walters, amigo personal del mariscal Humberto Castello Branco, y se envía al miembro de la CIA, Dan Mitrione, quien estaba a cargo de la organización del contrabando de armas para la formación de grupos paramilitares golpistas (Rapoport y Laufer 9).

La implicación del embajador Gordon en el proceso de acoso al gobierno de Goulart llegó al extremo de organizar y planear la "Operación Brother Sam", suspendida con posterioridad, que consistía en la movilización de una fuerza naval americana con base en Panamá en apoyo al levantamiento militar brasileño, lo que da fe de su protagonismo en el proceso golpista (Rapoport y Laufer 9-10).

Gordon sería ascendido a Secretario deEstado Adjunto para Asuntos Interamericanos en 1966, cesando como embajador en Brasil, pero continuando su política de injerencia directa en los asuntos del continente, adquiriendo gran protagonismo en Argentina (Rapoport y Laufer 10). Él es un referente clave para entender la actuación de la diplomacia estadounidense en el Cono Sur durante las dictaduras, por su abierta y

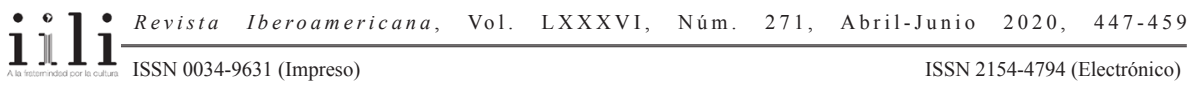


decidida actuación en los asuntos internos en los países de esta área, que revela un profundo conocimiento de la realidad social de estos países y sus excelentes conexiones con las élites económicas y el ejército, y una clara intencionalidad de cumplir un proyecto claramente diseñado. Sin ser, necesariamente, el prototipo del embajador estadounidense, sí marca las pautas de los valores y actuaciones de sus sucesores en el cargo.

En conclusión, lo que subyace en el fondo en ambas obras es un intento por desenmascarar formas opresivas, tanto políticas como culturales, con el objetivo de resaltar todo lo que de inhumano y degradante tienen los regímenes militares latinoamericanos. Representan, a la vez, un esfuerzo por esclarecer las interrelaciones entre la represión fascista, los intereses de las minorías dominantes, y la subordinación a políticas continentales, en cuanto estos sistemas políticos nacen de un egoísta e irresponsable concepto del patriotismo, que no duda en buscar apoyos en gobiernos e instituciones extranjeras, con el resultado de la neocolonización política, económica y cultural.

Sin embargo, aunque las dos novelas intentan transmitir una imagen compleja y totalizadora de la dictadura, adolecen de cierta falta de profundidad a la hora de reflejar la actuación y las responsabilidades de los actores fundamentales que protagonizaron tanto la aparición de los regímenes dictatoriales en Brasil como el proceso de represión, lo que atenúa y desvirtúa su mensaje de denuncia.

\section{OBRAS CITADAS}

"Antônio Callado chega aos 80 e revê obra". Entrevista por Matinas Suzuki y Maurício

Stycer. Folha de São Paulo(1997). <http://www1.folha.uol.com.br/fsp/1997/1/26/ brasil/14.html> 11 out. 2016.

Arrigucci Júnior, Davi. Achados e perdidos: ensaios de crítica. São Paulo: Polis, 1979. Callado, Antônio. Bar Don Juan. 1971. Rio de Janeiro: Civilização Brasileira, 1982. Quarup. Rio de Janeiro: Civilização Brasileira, 1967. Reflexos do baile. 1976. Rio de Janeiro: Paz e Terra, 1977. Sempreviva. Rio de Janeiro: Editora Nova Fronteira, 1981.

Chaves, Vânia Pinheiro. "História estilhaçada, romance em fragmentos: Reflexos do baile, de Antônio Callado". Revista do Centro de Estudos Brasileiros 4 (2003): 43-46.

Cruz, Cláudia Helena da. "ADitadura militar brasileira à luz dos romances engajados de Antônio Callado: um estudo de Quarup (1967), Bar Don Juan (1971), Reflexos do baile (1976) e Sempreviva (1981)". Anais do XIX Encontro Regional de História: Poder, Violência e Exclusão (2008): 1-11.

Gabeira, Fernando. O que é isso, companheiro? 1979. São Paulo: Schwarcz, 1998.

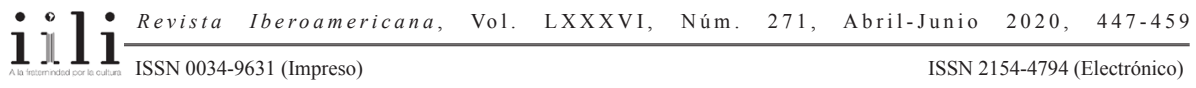


Penna Filho, Pio. "O Itamaraty nos anos de chumbo: O Centro de Informações do Exterior (CIEX) e a repressão no Cone Sul (1966-1979)". Revista Brasileira de Política Internacional 52/2 (2009): 43-62.

Rapoport, Mario y Rubén Laufer. "Los Estados Unidos ante el Brasil y la Argentina: los golpes militares de la década del 60". Estudios interdisciplinarios de América Latina y el Caribe 11/2 (2000): 63-91.

Palavras-chave: Antônio Callado; Fernando Gabeira; dictadura; guerrilla; Estados Unidos; literatura y periodismo

Recebido: $\quad 30$ outubro 2016

Aprovado: $\quad 15$ maio 2017 
